\title{
Cervical Cancer Prevention: Unearthing the Unspoken Barriers for Caribbean Women
}

\author{
Anniesha D. Noel-Smith, MD, MPH${ }^{1}$ and Shivaughn M. Hem-Lee-Forsyth, PhD, MPH ${ }^{2 *}$ \\ ${ }^{1}$ Department of Pediatrics, Advent health Orlando, Florida, USA \\ ${ }^{2}$ Department of Public Health and Preventative Medicine, School of Medicine, St. George's University, Grenada
}

Submission: June 12, 2021; Published: June 22, 2021

*Corresponding author: Shivaughn Hem-Lee-Forsyth, Department of Public Health and Preventive Medicine, St. George's University, Grenada

\begin{abstract}
Despite the introduction of effective screening mechanisms and the HPV vaccine in the Caribbean, the incidence and mortality from cervical cancer remains disproportionately higher than the rest of the world; the average incidence almost double the global average and is estimated to rise by more than $75 \%$ in the next 20 years. This review aims to explore the reasons that cervical cancer prevention services are underutilized within the region. A search of PubMed and Cochrane databases, and Google Scholar was done to identify relevant articles. Results showed that a lack of awareness and the resulting misconceptions about cervical cancer and its prevention; low literacy levels; fear of the procedure; and a negative diagnosis were factors that influenced use of prevention services in the Caribbean. Additionally, social factors such as stigma attached to HPV and cancer, physician-related barriers such as communication style and gender, and the health system defects were prominent contributors to the problem. Widespread and aggressive education beginning at the secondary school level; open discussion of cancer-related topics to dispel stigma; reconsidering materials used for dissemination of information; and addressing physician related barriers through use of female chaperons are some of the ways to improve utilization of services. These interventions can increase cervical cancer prevention programs' effectiveness and women's participation in the Caribbean, thus reducing the incidence and mortality from cervical cancer in the region.
\end{abstract}

Keywords: Uterine cervical neoplasms; Caribbean women; Prevention; Papanicolaou test; Papillomavirus infections; HPV vaccination

\section{Introduction}

Cervical cancer ranks globally as the fourth most common malignancy in women with over 570,000 new cases and 311,000 deaths annually [1,2]. This follows breast, colorectal and lung cancer [1]. In Latin America and the Caribbean (LAC), cervical cancer is ranked third, though ranking may vary by individual countries [2]. The LAC region has reported some of the highest incidence and cause specific mortality rates from cervical cancer in the world [3]. The latest estimate from 2019 noted that annually over 56,000 women are diagnosed with cervical cancer, an incidence of $13 \%$; this is projected to rise by over $75 \%$ in the following 20 years [4-6]. Moreover, annually 28,000 deaths occur which represents a cause-specific mortality of $10.4 \%[5,6]$. The LAC region represents $14.6 \%$ and $11.9 \%$ of global cervical cancer cases and deaths respectively; the average incidence rate double that of the worldwide average [4].

In the Caribbean, cervical cancer accounts for a significant number of cancer-related deaths. It is ranked in most Caribbean countries as the second most common cause of cancer-related deaths. Exceptions include Antigua and Barbuda where it is ranked number four, Barbados and Bahamas which ranks it number three, and in Belize and Suriname where it is the number one cause of cancer-related deaths [7]. Amongst the English- and Dutch-speaking Caribbean countries in particular, cervical cancer accounted for $4.5 \%$ to $18.2 \%$ of all cancer related deaths from the period $2003-2013$ [8]. Additionally, cervical cancer is a significant cause of lost years of life as cervical cancer mainly affects women 20-64 years old. It accounted for 314,000 lost years of life in 2000 in the LAC, more than twice the global average and more than diseases like breast cancer, or maternal illnesses [9]. Estimates on the burden of cervical cancer in the Caribbean region beyond 2013 are very limited; however, based on the available statistics and the projected increase, it can be concluded that this burden is a public health concern warranting emergent attention.

The development of the human papillomavirus (HPV) vaccine, and screening techniques such as Pap Smears and Colposcopy have made cervical cancer one of the most preventable cancers 
to date [3]. Since their introduction on the global market, several Caribbean governments have implemented them, beginning in 1987, to reduce cervical cancer rates in the region [5]. National screening programs are present and widely accessible in most Caribbean islands. The Pap Smear is the most common screening modality though Visual Inspection with Acetic Acid is also used in Belize and Guyana [5,7]. Barbados has replaced the conventional Pap Smear with the ThinPrep Pap test, a more sensitive and specific test for Cervical cancer than the conventional Pap Smear [3]. HPV testing is yet to be included as part of the national screening program in Caribbean [7]. With respect to immunization, many of the English-speaking Caribbean states have included the HPV vaccine into their national immunization program $[7,10]$. Table 1 gives a summary of the prevention services and their coverage currently available in the Caribbean. Additionally, Belize and Surinam have implemented a dedicated budget to finance cervical cancer prevention and treatment services [5].

Despite these initiatives, women are opting out of screening or vaccination which has slowed efforts to reduce cervical cancer mortality. The percentage of women in LAC eligible for cervical cancer screening who have received a Pap smear was noted to be under 50\% [11]. Within the Caribbean, screening coverage rates between $10 \%$ and 50\% were reported in 2016 in St. Kitts \& Nevis,
Jamaica, Guyana, and Belize. St. Lucia's coverage was less than $10 \%$ and Dominica reported the highest coverage of $70 \%$ in 2016 [12]. Trinidad and Tobago's last reported coverage was $35.4 \%$ in 1987 and data from other Caribbean islands were unknown or not available [12,13]. Several studies have been conducted globally evaluating the reasons for underutilization of these prevention services in women and have listed a number of contributing factors [14-17]. Chidyaonga et al. [17] noted that these factors occur at three levels: individual, community and at the health system level.

Individual level factors include fear and embarrassment; level of awareness or knowledge of prevention services; socioeconomic status; age; marital status; literacy; cultural and religious ideologies. At the community level, discussion around reproductive health issues is taboo; and language barriers of immigrants affect their awareness and utilization of services. Health system factors include center location, cost and delivery method of services; lack of female physicians for test administration and limited health provider recommendations $[3,14,15,17,18]$. This paper seeks to bring to the forefront the factors affecting Caribbean women's desire to readily utilize the cervical cancer prevention services in their community. Knowledge and understanding of these barriers can assist with the formulation of effective cervical cancer prevention programs in this region (Table 1).

Table 1: National Prevention programs in some Caribbean States.

\begin{tabular}{|c|c|c|c|}
\hline Caribbean Territory & Screening Program & $\begin{array}{c}\text { Screening program Cov- } \\
\text { erage }(\%)\end{array}$ & HPV vaccination (Year initiated) \\
\hline Trinidad \& Tobago & Pap smear ${ }^{7}$ & $\mathrm{~N} / \mathrm{A}^{12}$ & Yes; $2013^{7}$ \\
\hline Suriname & $\mathrm{N} / \mathrm{A}$ & $\mathrm{N} / \mathrm{A}$ & This should read Yes; $2013^{7,10}$ \\
\hline St, Vincent \& the Grenadines & Pap smear ${ }^{7}$ & $\mathrm{~N} / \mathrm{A}$ & $2017^{10}$ \\
\hline Guyana & VIA7 & $10-50^{12}$ & Yes; subnational $2012^{7}$; fully $2017^{10}$ \\
\hline Jamaica & Pap smear ${ }^{7}$ & $10-50^{12}$ & Yes; $2017^{10}$ \\
\hline St. Kitts \& Nevis & Pap smear ${ }^{7}$ & $10-55^{12}$ & $\mathrm{~N} / \mathrm{A}$ \\
\hline Grenada & Pap smear $^{7}$ & $\mathrm{~N} / \mathrm{A}^{12}$ & Yes; $2019^{10}$ \\
\hline Dominica & Pap smear ${ }^{7}$ & $>70^{12}$ & Yes; $2019^{10}$ \\
\hline Barbados & Thin Prep pap test ${ }^{3}$ & $\mathrm{~N} / \mathrm{A}^{12}$ & Yes; $2014^{7}$ \\
\hline Bahamas & Pap smear ${ }^{7}$ & $\mathrm{~N} / \mathrm{A}^{12}$ & Yes; $2015^{7}$ \\
\hline Antigua \& Barbuda & Pap smear $^{7}$ & $\mathrm{~N} / \mathrm{A}^{12}$ & Yes; $2016^{7}$ \\
\hline St. Lucia & Pap smear $^{7}$ & $<10^{12}$ & Yes; $2019^{10}$ \\
\hline
\end{tabular}

\section{Methods}

A review of the literature was conducted to determine the factors contributing to the underutilization of cervical cancer prevention services by Caribbean women. Several databases and search engines were searched including PubMed, Google Scholar, and Cochrane databases and Google in September 2020, using key words with Boolean operators: cervical neoplasm, Caribbean, prevention, prevalence, incidence, socioeconomic, psychological factors, pap smear. No date or language filters were applied on initial search. Moreover, references of acquired articles were screened for supplemental publications relevant to our study, leading to a total of 157 articles. These articles were then screened to see if they met the inclusion criteria.

Publications were included if they were peer-reviewed publications or publications from governmental or regional health department, contained full text, and data on Caribbean women. Publications were rejected if they were not in English as full text translations were not available; had no full text; were letters to the editor or books; contained duplicated data on the same population; or did not contain data on our target population. 
For the purposes of this study, Caribbean women were defined not only as women living within the geographical boundaries of the Caribbean, but also included those who self-identified as belonging to the Caribbean diaspora. After screening, 33 articles were selected for this analysis.

\section{Discussion}

Traditionally, Caribbean society depends on women filling vital roles as primary caregivers, household leaders and contributors to the workforce. As such, the increased mortality caused by cervical cancer in young women negatively impacts family life along with national productivity and sustainability. Addressing cervical cancer mortality and promoting greater use of cervical cancer prevention services is needed. However, this is not possible without a thorough understanding of the unspoken barriers influencing women's decisions to not utilize these services [3]. Barriers to participation noted amongst Caribbean women include lack of awareness or knowledge about cervical cancer and its prevention, fears and attitudes towards cervical cancer, societal expectations, socioeconomic status, health system factors and costs of services. Additionally, religious beliefs, gender perspectives and socio-cultural factors are also influential [19].

In examining Caribbean women's awareness of the factors causing cervical cancer, the following was found. Studies in the Caribbean show that approximately $76.5 \%$ and $17.9-80 \%$ of women knew about cervical cancer and pap smears respectively, but only $5.6 \%$ were aware of the HPV vaccine $[19,20]$. Lack of awareness has led to the formation of many misconceptions about cervical cancer's etiology, prognosis, and prevention. Some women believe that cervical cancer is caused by poor hygiene and dietary choices, miscarriages, vaginal infections, intra-uterine contraceptives, sexual abuse and by semen [21,22]. Additionally, some believe that it is hereditary or that the diagnosis means inevitable death $[3,19]$.

With respect to pap smears, there is the misconception that it identifies abnormal bacteria in the body, and detects sexually transmitted infections, bacterial and yeast infections. It is also believed to indicate the status of women's reproductive and sexual health, an association that Christian \& Guell [3] found unique to Caribbean women. One explanation for this belief is that most pap smears are done during routine postnatal clinic appointments. As such, nulliparous women did not see the need for pap smears [3]. Moreover, some women are unaware that pap smears detected precancerous lesions and thus helped prevent cervical cancer [23]. Many teenage women between 15 to 17 years old are also unaware of the link between HPV and sexual intercourse and the subsequent importance of the HPV vaccine in preventing cervical cancer [24]. These findings suggest that the knowledge women possess about cervical cancer is not only limited but, in some cases, inaccurate. Consequently, prevention services will not be adequately utilized if women are not convinced of its importance, or aware of the facts pertaining to cervical cancer. It is therefore imperative that education on disease risk, transmission and prevention should be at the forefront of any cervical cancer prevention strategy.

The lack of education on cervical cancer and its prevention has been associated with the level of formal education received by women. Women with higher education are more knowledgeable on cervical cancer, and more likely to have screenings done than women with less formal schooling $[15,20,25,26]$. One explanation for this phenomenon is that increased education tends to improve cognitive functioning, and thus more educated women make more informed decisions toward their healthcare and lifestyles [25].

Low literacy levels impair doctor-patient communication and patients' inability to follow healthcare provider recommendations as these persons lack comprehension or knowledge of healthrelated concepts [25,27]. Low literacy also renders cancer prevention information given ineffective as they are most often disseminated via written materials, such as brochures and postures, in grade 11 and upwards language. Women who are unable to read would be less likely to take the necessary action advised in the written material $[25,27]$. Hence, addressing literacy levels in Caribbean women is important, and should include studies examining the association between low literacy levels and Caribbean women's response to cervical cancer related topics. It should also prompt physicians and public health officials to reexamine their campaign and information dissemination methods in areas with low literacy.

Fear and stigma also negatively affect the use of screening services. Unpleasant previous medical encounters: negative anecdotes provided by family and friends; and the taboo nature of HPV and cancer contribute to the fear of screening. Women are fearful of the procedure which they have described as painful, uncomfortable, and embarrassing $[15,28,29]$ Due to the taboo nature of HPV and cancer, there is a stigma attached to persons who receive abnormal results. HPV is associated with promiscuity and infidelity; it can result in disrupted relationships to the point of divorce [30].

On the other hand, cancer may also be associated with inevitable death and few women are aware of the possible treatments available once diagnosed [19,30,31]. For this reason, many women prefer to remain oblivious about their cervical cancer status even if cancer could be present and thus delayed getting screening [31]. Older women appear to be more concerned with the opinions of their peers and the anticipated shame acts as a barrier to screening [22]. These studies, however, do not provide an in-depth analysis into the origins of the misconceptions and taboo surrounding cervical cancer and HPV in the Caribbean. By understanding why these attitudes exist, it will be possible to formulate targeted educational programs to treat with these issues. 
Another reason for low uptake is physician-related barriers $[31,32]$. Physician related barriers include the gender of the physician; communication style; and the lack of recommendations or reminders provided by the physician to patients. Women are more comfortable discussing body-related matters with female health providers than with male health-providers [32]. Communicating information about cervical cancer to patients in an impersonal manner also acts as a deterrent for many women [19]. Moreover, according to Hyman et al. [32], female physicians are more likely to recommend screening services to women but, even when they do, adequate reminders are not given.

Lastly, Ncube et al. [29] and Hyman et al. [32] noted that system level factors such as screening or vaccination costs; lack of knowledge on screening sites; distance from testing site; and socioeconomic and marital status influenced women's use of these services. In countries where pap smears are not available to women free of charge, paying out-of-pocket can be costly especially if reimbursements are not provided [32]. With regards to socioeconomic status, women in the lower socioeconomic classes are less likely to have a Pap smear than women of a higher status [11]. The same was also noted for unemployed women; women from larger households; and older women who led households [26]. Similarly, with regards to marital status, Ncube et al. [29] noted that married women were much more likely to get a pap smear than single women, largely due to support from their spouses (Table 2).

Table 2: Attitudes about pap smear by Caribbean women who have never had a pap smear.

\begin{tabular}{|c|c|c|c|c|c|c|}
\hline Author & $\begin{array}{c}\text { Sample } \\
\text { Size }\end{array}$ & $\begin{array}{c}\text { Study Loca- } \\
\text { tion }\end{array}$ & $\begin{array}{c}\text { Fear of Test } \\
\mathbf{( \% )}\end{array}$ & $\begin{array}{c}\text { Fear of Diag- } \\
\text { nosis (\%) }\end{array}$ & $\begin{array}{c}\text { Need More Infor- } \\
\text { mation (\%) }\end{array}$ & $\begin{array}{c}\text { Need More Time } \\
\text { with Provider } \\
\text { (\%) }\end{array}$ \\
\hline Ncube et al. $2015^{29}$ & $138 / 403$ & Jamaica & 46.7 & 36.5 & 46.7 & 40.9 \\
\hline Bessler et al. $2007^{15}$ & $41 / 367$ & Jamaica & 56.3 & 40.6 & 65.6 & 21.9 \\
\hline Bourne et al. $2010^{35}$ & & Jamaica & 1.4 & - & - & - \\
\hline
\end{tabular}

\section{Recommendations}

The low uptake of cervical cancer prevention services by Caribbean women is disturbing. Encouraging the utilization of these services is crucial to early detection and treatment. The barriers identified within the Caribbean are remarkably similar to those experienced globally. Research conducted outside the region has suggested several successful interventions that may be used to improve utilization of cervical cancer prevention services with similar success in the Caribbean. These interventions seek to better inform women on the topic and create a more comfortable patient care experience. Educational programs have been found to be significantly effective at increasing uptake [33]. Widespread education particularly at the community level can dispel misconceptions about cervical cancer causes, cancer diagnosis, and screening [22]. Additionally, information on HPV and cervical cancer should be included in secondary school health education programs to increase awareness at an earlier age [24]. Topics related to cervical cancer, HPV, pap smears, and the HPV vaccine should be discussed openly in communities and homes to dispel the stigma associated with them. For women opposed to pelvic examinations because they are painful or uncomfortable, vaginal sampling collected by the patient at home was an alternative explored by a Chilean study that can be used to increase participating rates [34]. Additionally, it was also noted that having a health provider with whom patients have a good rapport can help women feel more relaxed and comfortable during the procedure [22].
Addressing physician related barriers by providing female chaperones; and screening recommendations at clinic visits with sufficient reminders can potentially increase use of cervical cancer services by Caribbean women. Recommendations for screening should not be limited to postnatal visits but should also be an integral part of women's well-visit appointments. Additionally, investment into training programs on communication and patient education for healthcare professionals should encourage compliance with preventions measures [22]. More information on the policies and interventions currently used by Caribbean governments to increase use of cervical cancer prevention services needs to be made public. To date, available information is sparse, and hence policy cannot be properly formulated. For example, Barbados has announced plans to decrease the number of times that women visit health care facilities for screening, however, additional information about the implementation or outcome of these plans was not publicly available [5]. Belize and Guyana introduced visual inspection with acetic acid screening program into the population, but information on the effectiveness and its impact on improving cervical cancer screening coverage were not publicly available [7]. If Caribbean governments provide data and/ or information on their initiatives, it would be possible to measure the impact of different strategies and thus develop more effective policies in the future.

The literature also identified the need for investigation into the effectiveness of intervention strategies used to prevent cervical cancer within the Caribbean. Several of the studies examining 
effective interventions were done in developed countries. Given that the resources, culture, and population demographic of developing countries vary from developed countries, proposed interventions may not be as effective or implementable in developing countries [33]. Thus, before adoption of proposed interventions, research is required on the cost effectiveness, cultural appropriateness and applicability of these interventions within the socioeconomic context of the Caribbean. Furthermore, insufficient information is available in the literature on the most effective types of educational interventions for increasing uptake. Research examining different programs and methods of information dissemination and their effectiveness across different ethnic groups, socioeconomic class and geographical location is required. Future studies should also explore new intervention strategies for increasing uptake and evaluate if these strategies influence the decision-making process [33].

The barriers mentioned in this review are not exhaustive. There is a need to not only identify additional barriers not previously mentioned in the literature, but to also provide an indepth analysis into the historical origins of the misconceptions and taboo surrounding cervical cancer, and HPV in the Caribbean. Furthermore, international, and local studies investigating new approaches to cervical cancer screening can be done to make screening and vaccination simpler and more attainable [34,35].

This review also has limitations with the most significant being insufficient up-to-date data. The available data came from Trinidad and Tobago, Jamaica, Barbados, Grenada, and the Caribbean diaspora. Consequently, any generalization from this population to the wider Caribbean is limited, as many states were not accounted for. Additionally, the available data was outdated with the most recent statistic on cervical cancer in the Caribbean reported in 2015. Furthermore, many of these statistics came from non-governmental resources and as such, the validity of the data is limited. For a more generalized assessment research on the factors hindering women from accessing screenings and vaccination, a publicly available dataset by Caribbean governments should be created and consistently kept up to date. Despite these limitations, this review brings light to the perceptions, socioeconomic and cultural factors that act as barriers to Caribbean women getting screened or vaccinated for cervical cancer.

\section{Conclusion}

Cervical cancer has a high prevalence among Caribbean women although it is regarded as a preventable cancer due to the availability of screening and vaccination. Though these services are to a great extent available to Caribbean women, the uptake is low. This has been attributed to the many misconceptions secondary to lack of knowledge, literacy levels, attitudes and beliefs towards cervical cancer, physician-related and organizational barriers that exist. Understanding these barriers can lead to the formulation of strategic policies and social marketing initiatives which address these barriers to encourage increased participation. This study has underscored the need for further research on effective strategies that are relevant to Caribbean women and in a larger patient population to gain a more generalized picture. Additionally, future studies are needed on novel screening methods and additional barriers for low uptake. Lastly, this study highlights the need for current statistics and government policies which are publicly accessible to assist with the research process.

\section{References}

1. Arbyn M, Weiderpass E, Bruni L, de Sanjosé S, Saraiya M, et al. (2020) Estimates of incidence and mortality of cervical cancer in 2018: A worldwide analysis. Lancet Glob Health 8(2): e191-e203.

2. Pilleron S, Cabasag CJ, Ferlay J, Bray F, Luciani S, et al. (2020) Cervical cancer burden in Latin America and the Caribbean: Where are we? Int J Cancer 147(6): 1638-1648.

3. Christian T, Guell C (2015) Knowledge and attitudes of cervical cancer screening among Caribbean women: A qualitative interview study from Barbados. Women Health 55(5): 566-579.

4. Parkin DM, Almonte M, Bruni L, Clifford G, Curado MP, et al. (2008) Burden and Trends of Type-Specific Human Papillomavirus Infections and Related Diseases in the Latin America and Caribbean Region. Vaccine 26(Suppl 11): L1-L15.

5. Pan American Health Organization (2013) Situational analysis of cervical cancer prevention and control in the Caribbean.

6. Pan American Health Organization (2019) Cervical cancer is the third most common cancer among women in Latin America and the Caribbean, but it can be prevented.

7. Luciani S, Hutton M, Hennis A, Hassell T (2017) Cancer prevention and control in the Caribbean. Cancer Control, pp. 65-72.

8. Razzaghi H, Quesnel-Crooks S, Sherman R, Joseph R, Kohler B, et al. (2016) Leading Causes of Cancer Mortality - Caribbean Region, 20032013. Morb Mortal Wkly Rep 65(49): 1395-1400.

9. Yang BH, Bray FI, Parkin DM, Sellors JW, Zhang ZF, et al. (2004) Cervical cancer as a priority for prevention in different world regions: an evaluation using years of life lost. Int J Cancer 109(3): 418-424.

10. Tsu V, LaMontagne D, Atuhebwe P, Bloem P, Ndiaye C, et al. (2021) National implementation of HPV vaccination programs in low-resource countries: Lessons, challenges, and future prospects. Prev Med 144: 106335 .

11. Liebermann EJ, VanDevanter N, Hammer MJ, Fu MR (2018) Social and Cultural Barriers to Women's Participation in Pap Smear Screening Programs in Low- and Middle-Income Latin American and Caribbean Countries: An Integrative Review. J Transcult Nurs 29(6): 591-602.

12. Pan American Health Organization (2016) Women's Cancer and Comprehensive Care in the Caribbean Situation and Challenges.

13. Franco EL, Tsu V, Herrero R, Lazcano-Ponce E, Hildesheim A, et al (2008) Integration of Human Papillomavirus Vaccination and Cervical Cancer Screening in Latin America and the Caribbean. Vaccine 26(Suppl 11): L88-L95.

14. Bingham A, Bishop A, Coffey P, Winkler J, Bradley J, et al. (2003) Factors affecting utilization of cervical cancer prevention services in lowresource settings. Salud Publica Mex 45(Suppl 3): S408-416.

15. Bessler P, Aung M, Jolly P (2007) Factors affecting uptake of cervical cancer screening among clinic attendees in Trelawny, Jamaica. Cancer Control 14(4): 396-404. 
16. Adamu AN, Abiola AO, Ibrahim Mto (2012) The effect of health education on the knowledge, attitude, and uptake of free Pap smear among female teachers in Birnin-Kebbi, North-Western Nigeria. Niger J Clin Pract 15(3): 326-332.

17. Chidyaonga-Maseko F, Chirwa ML, Muula AS (2015) Underutilization of cervical cancer prevention services in low and middle income countries: a review of contributing factors. Pan Afr Med J 21: 231.

18. Bynum SA, Wigfall LT, Brandt HM, Julious CH, Glover SH, et al. (2016) Social and structural determinants of cervical health among women engaged in HIV care. AIDS Behav 20(9): 2101-2109.

19. Lewis MJ (2004) Situational analysis of cervical cancer in Latin America \& the Caribbean. Pan American Health Organization, Washington DC, USA, pp. 1-28.

20. Chekuri A, Bassaw B, Affan AM, Habet, G, Mungrue K, et al. (2012) Knowledge, attitudes, practice on human papilloma virus and cervical cancer among Trinidadian women. J Obstet Gynaecol 32(7): 691-694.

21. Paz-Soldán VA, Bayer AM, Nussbaum L, Cabrera L (2012) Structural barriers to screening for and treatment of cervical cancer in Peru. Reprod Health Matters 20(40): 49-58.

22. Marlow LAV, Waller J, Wardle J (2015) Barriers to cervical cancer screening among ethnic minority women: a qualitative study. J Fam Plann Reprod Health Care 41(4): 248-254.

23. Barnett DB (1996) Cervical cancer screening programs technical cooperation in the Caribbean. Bull Pan Am Health Organ 30(4): 409 412.

24. George C, Roberts R, Brennen D, Deveaux L, Read SE, et al. (2020) Knowledge and awareness of human papillomavirus (HPV) and HPV vaccines among Caribbean youth: the case of the Bahamas. Hum Vaccin Immunother 16(3): 573-580.

25. Reyes-Ortiz CA, Camacho ME, Amador LF, Velez LF, Ottenbacher KJ, et al. (2007) The Impact of Education and Literacy Levels on Cancer Screening among Older Latin American and Caribbean Adults. Cancer Control 14(4): 388-395.
26. Rawlins J, Crawford T (2006) Women's health in the English-speaking Caribbean: The case of Trinidad and Tobago. Soc Econ Stud 55(4): 1-31.

27. Lindau ST, Tomori C, Lyons T, Langseth L, Bennett CL, et al. (2002) The association of health literacy with cervical cancer prevention knowledge and health behaviors in a multiethnic cohort of women. Am J Obstet Gynecol 186(5): 938-943.

28. Agurto I, Bishop A, Sánchez G, Betancourt Z, Robles S, et al. (2004) Perceived barriers and benefits to cervical cancer screening in Latin America. Prev Med 39(1): 91-98.

29. Ncube B, Bey A, Knight J, Bessler P, Jolly PE, et al. (2015) Factors associated with the uptake of cervical cancer screening among women in Portland, Jamaica. N Am J Med Sci 7(3): 104-113.

30. Liebermann EJ, VanDevanter N, Shirazian T, Frías Gúzman N, Niles M, et al. (2020) Barriers to Cervical Cancer Screening and Treatment in the Dominican Republic: Perspectives of Focus Group Participants in the Santo Domingo Area. J Transcul Nurs 31(2): 121-127.

31. Marlow LAV, McGregor LM, Nazroo JY, Wardle J (2014) Facilitators and barriers to help-seeking for breast and cervical cancer symptoms: a qualitative study with an ethnically diverse sample in London. Psychooncology 23(7): 749-757.

32. Hyman I, Singh PM, Meana M, George U, Wells LM (2002) Physicianrelated determinants of cervical cancer screening among Caribbean women in Toronto. Ethn Dis 12(2): 268-275.

33. Everett T, Bryant A, Griffin MF, Martin-Hirsch PP, Forbes CA, et al. (2011) Interventions targeted at women to encourage the uptake of cervical screening. Cochrane Database Syst Rev, 2011(5): CD002834.

34. Herrero R, Ferreccio C, Salmerón J, Almonte M, Sánchez GI, et al. (2008) New Approaches to Cervical Cancer Screening in Latin America and the Caribbean. Vaccine 26 (Suppl 11): L49-L58.

35. Bourne P, Charles C, Francis C, South-Bourne N, Peters R, et al. (2010) Perception, attitude, and practices of women towards pelvic examination and pap smear in Jamaica. N Am J Med Sci 2(10): 478-486.

\section{Your next submission with Juniper Publishers will reach you the below assets}

- Quality Editorial service

- Swift Peer Review

- Reprints availability

- E-prints Service

- Manuscript Podcast for convenient understanding

- Global attainment for your research

- Manuscript accessibility in different formats

( Pdf, E-pub, Full Tsext, Audio)

- Unceasing customer service

Track the below URL for one-step submission https://juniperpublishers.com/online-submission.php 